This is an Accepted manuscript of an article published by Elsevier in Decision Support Systems in Dec 2012, available online: https://doi.org/10.1016/j.dss.2012.07.002

\title{
IT as enabler of sustainable farming: an empirical analysis of farmers' adoption decision of precision agriculture technology
}

Benoit A Aubert, Andreas Schroeder, Jonathan Grimaudo

\begin{abstract}
Precision agriculture (PA) describes a suite of IT based tools which allow farmers to electronically monitor soil and crop conditions and analyze treatment options. This study tests a model explaining the difficulties of PA technology adoption. The model draws on theories of technology acceptance and diffusion of innovation and is validated using survey data from farms in Canada. Findings highlight the importance of compatibility among PA technology components and the crucial role of farmers' expertise. The model provides the theoretical and empirical basis for developing policies and initiatives to support PA technology adoption.
\end{abstract}

\section{Keywords}

Precision agriculture, Sustainable Farming, Adoption, Characteristics of Innovation, Technology Acceptance

\section{INTRODUCTION}

Farming operations entail complex decision making problems, characterized by considerable levels of uncertainty and alternative courses of action [57]. A crop farmer needs to consider a variety of parameters such as crop yield, availability of water and nutrients, and a range of site- and soil-specific factors to optimize the plant treatment (e.g. application of fertilizer, pesticides, or irrigation). A high variability of these parameters within a single field further complicates the optimization of the plant treatment. The 
common practice of regarding the field as a homogenous entity creates a sup-optimal treatment, often leading to an oversupply of nutrients and pesticides [3]. Sub-optimal treatments create considerable costs for farmers and constitute a major source of environmental pollution [51].

Recent information technology (IT) based innovations support farmers in their decision making and operations. The notion of precision agriculture (PA) summarizes the use of IT applications to electronically monitor soil and crop conditions and to target the treatment with high level of detail. PA technology allows farmers to recognize variations of time and space in the production resources and to apply treatment with a much finer degree of precision than previously possible [31]. The emergence of PA technology represents a paradigm shift in farming practices: it permits the consideration of the field as a heterogeneous entity that allows for selective treatment instead of a homogenous entity that requires indiscriminate care. By allowing for sophisticated analysis of production resources and selective treatment, PA technology is recognized as a major contributor to farming efficiency and environmentally sustainable farming practice. PA technology can lead to drastic reductions in the use of contaminants (by more than 90\%) [21]. The technology creates significant opportunities to improve efficiency in farming operations and contributes to environmental sustainability.

Despite the availability of tools and applications that support sophisticated decision making and operation, the uptake of PA technology among farmers remains surprisingly low [9]. For example, Reichardt, Jürgens, Klöble, et al [58] report an adoption rate of less than $10 \%$ among German farmers. To explain the low PA technology adoption prior studies examined a range of individual factors influencing a farmer's adoption decision although the interaction and relationships among the different factors were not considered [e.g. 46,68]. Given the importance of profitable and environmentally sustainable farming practices, a sophisticated analysis of PA technology adoption is required. A sound understanding of the complexity of PA adoption is necessary in order to develop adequate policies and initiatives which support the adoption of PA technology. 
The present research drawing on data collected from Canadian farmers, the paper provides numerous contributions. By qualifying PA technology as a type III information systems innovation [65] the study explores the adoption of a complex technology that integrates information system innovation with core business technology. Hence, the study contributes to a growing body of research focusing on adoption of technology and new business processes at the same time, joining a relatively limited number of adoption studies focusing on type III innovations [e.g. 11,12,74].

The model draws on the established diffusion of innovation [47,59] and technology acceptance literature [18]. In order to reflect the complex nature of such innovation, the research also includes the identification of several variables like social influence and individual characteristics, as recommended by Khalifa and Shen [37]. Thus, the investigation provides a sound theoretical and empirical basis for understanding the complexity of the PA technology adoption decision. In addition, the design of the adoption variable reflects the incremental character of the PA technology adoption; PA technology is made of several components, which can be adopted in sequence. These elements provide a more complete understanding of the adoption decision and increase our understanding of the adoption of complex innovations.

The study seeks to improve decision making and extend IS research in sectors that, although important, had traditionally been less often investigated than others. The agricultural sector has received far less attention in comparison to the financial and manufacturing sector despite its critical role in securing our food supply and the strong potential contribution of IT in agriculture [13]. Results offer avenues for technology vendors and farming associations to improve the use of IT in the agriculture sector.

The study further contributes to the growing research interest in Green IT (a research focus which receives increasing attention in leading research outlets [42]. It shows how IS can contribute to sustainable development beyond immediate commercial benefits. Results provide many elements that can guide policy development. These policy implications can benefit the farmers by making the PA adoption context more 
favorable. They can also benefit the population in general by inducing farmers to adopt PA technology and reduce their use of water and numerous pollutants.

An interesting feature of the research is that it assesses the actual adoption of the technology, within its work context, rather than the intention to adopt as most studies do [e.g. 66]. Results show that resource availability is the most influential factor for adoption of PA technology. This factor is more influential than the ease of use and the usefulness generally considered, although both show significant influence. Individual characteristics of the farmer, notably its education and general innovativeness, are also influential factors.

The remainder of the paper is structured as follows: First, the literature on precision agriculture is reviewed to introduce the relevant technologies and the implications of their adoption. Second, the extent adoption theory is discussed to conceptualize the PA adoption model and define its core constructs. Third, data collection and analysis are described and results discussed. The paper concludes by highlighting the contributions to IS research and the implications for policy makers and PA technology vendors.

\section{PRECISION AGRICULTURE}

Precision agriculture (PA) is formally defined as the "electronic monitoring and control applied to data collection, information processing and decision support for the temporal and spatial allocation of inputs for crop production" (p 371) [8]. PA technology supports a farmer's decision making with regards to the quantity of fertilizer to use depending on soil type, the type of culture to plant according to current soil conditions, and the quantity of pesticides to use on a specific crop. These kinds of decisions are based on diverse information sources and require sophisticated analysis as they will directly affect the quantity and

quality of the crop, the profitability of the operation, and its environmental impact. The core objective of PA is "to increase the number of (correct) decisions per unit area of land per unit of time with associated net benefits" ( $\mathrm{p} 8$ ) [45]. PA technology facilitates the collection of required data from the field, supports 
the data analysis and enables an adjustment of the farming practice. The range of technologies contributing to the data collection, decision making and management processes are commonly grouped into diagnostic and applicative technology families [46].

Diagnostic tools summarize the "methods of gathering data and analyzing spatial variability at the sub-field level" (p 24) [46]. This category includes global positioning systems (GPS), geographic information systems (GIS), yield monitors, and crop scouting or remote sensing systems (see details in Table 1). These tools create the integrated data source necessary to determine spatial variability in fields, nutrient requirements, and other field imbalances. Although a data source is essential for deriving decisions on farming practices, not all of these tools are required. Each tool provides a further dimension to the data source, enabling more sophisticated diagnostics.

Following the data collection and diagnostic processes applicative tools are used to allocate the required inputs on the field. Applicative tools are computer controlled devices which adjust input applications as machines move across the field [46]. The category includes variable rate application devices and guidance and navigation systems that direct the machines. The use of applicative tools requires prior use of diagnostic tools to create the data source on which to act. Hence, an adopter of applicative tools is necessarily an adopter of diagnostic tools. In general, farmers who have adopted PA technology are mostly focusing on map based approaches [73] using a combination of GPS for positional data, GIS for soil mapping, yield monitors for yield mapping and variable rate fertilizer applicators.

\section{Table 1: Description of PA Technologies}

\begin{tabular}{|l|l|l|}
\hline Name & Description & Category \\
\hline GPS: & $\begin{array}{l}\text { A global positioning system is used for topographic surveying or in } \\
\text { conjunction with other sensors to provide geo referenced (x, y } \\
\text { coordinate) maps of yield, salinity, or other measurable items and would } \\
\text { require mapping within a field crop. }\end{array}$ & $\begin{array}{l}\text { Diagnostic } \\
\text { tools }\end{array}$ \\
\hline GIS: & $\begin{array}{l}\text { A geographic information system is a database storing data such as soil } \\
\text { type and other location specific information. }\end{array}$ & \\
\hline
\end{tabular}




\begin{tabular}{|l|l|l|}
\hline Name & Description & Category \\
\hline $\begin{array}{l}\text { Yield } \\
\text { monitors: }\end{array}$ & $\begin{array}{l}\text { Yield monitors collect data across the crop fields to measure potential } \\
\text { variations. They can also collect protein and moisture data in the soil. } \\
\text { These monitors are available for most grain and bulk crop harvesters. }\end{array}$ & \\
\hline $\begin{array}{l}\text { Crop scouting } \\
\text { \& remote } \\
\text { sensing: }\end{array}$ & $\begin{array}{l}\text { Imaging devices are used to identify problems in the crop and make } \\
\text { records of sloughs, field boundaries, rocks, etc. }\end{array}$ & \\
\hline $\begin{array}{l}\text { Variable rate } \\
\text { application: }\end{array}$ & $\begin{array}{l}\text { These devices can apply fertilizer, seed, and pesticides using controllers } \\
\text { to vary the rate on the go. The devices can be computer controlled } \\
\text { according to a prescription map or varied manually. They are installed on } \\
\text { the sprayer, either as an add-on or pre-installed, in order to treat the crop } \\
\text { field. }\end{array}$ & Applicative \\
& $\begin{array}{l}\text { These systems can be used for parallel tracking while spraying or } \\
\text { swathing. The GPS navigation system can be used to return to a point } \\
\text { with known coordinates to spot spray, soil sample at the same location, } \\
\text { or return to a rock to pick up. }\end{array}$ & \\
\hline $\begin{array}{l}\text { Guidance and } \\
\text { navigation: }\end{array}$ & \multicolumn{1}{|l|}{ tools } \\
\hline
\end{tabular}

The adoption of PA technology is not limited to the introduction of technological tools but has implications for the underlying farming processes. The adoption of PA technology leads to a much larger emphasize on the analytical aspects of the farming operations and will likely change core farming practices as a consequence [62]. Innovation theory considers technological innovations that result in significant changes in core business processes and administrative practices as type III innovations [65] (as opposed to innovations that are limited to changes in the technology itself, Type I \& II). Other examples of type III innovations include e-business technology [74] or EDI technology [11] which are both deeply embedded in the core business processes of the adopting organizations. The wide implications of the PA technology decision on farming practice suggests a complex range of factors impacting on the adoption decision.

Several studies looked at the PA technology adoption decision. Studies have identified farm characteristics as important factors influencing the adoption decision. Farm size was found to positively impact on PA technology adoption, following considerations of economy of scale [46]. Borrowing capacity of the farm business was similarly identified as important criteria [22]. Location was also found to impact on the PA technology adoption decision which is explained by the higher vendor concentrations in specific areas [46]. PA adoption research has further focused on the farmer as the main decision maker. It was shown that farmer's education $[5,26,39,46]$ and risk management attitude $[2,46]$ impact on the adoption decision. An 
increase in the farmer's age reduces the likelihood of PA adoption [17]. Further factors impacting the adoption are the complementarity of the technology and the access to information source such as crop consultants and associations [46].

\section{CONCEPTUALIZING A PA ADOPTION MODEL}

The present research develops and tests a model explaining the adoption of PA technology. Prior studies investigating PA technology adoption provided valuable insights. However, these studies considered a limited set of explanatory factors. Adoption of type III innovations is a strategic decision with long term implications [65]. To create an understanding of PA technology adoption that takes the complexity of the adoption decision and the particular characteristics of the PA technology into account we integrate established adoption theory with insights from the PA context.

In order to explain Type III innovation adoption, the consideration of factors that are specific to the technology is required [23]. Our investigation of PA technology adoption draws on diffusion of innovation theory and technology acceptance theory as the two main streams of technology adoption research [48] and integrates factors that are derived from prior PA research.

Diffusion of innovation (DOI) theory focuses on the attributes of an innovation to explain the variance in its adoption. It stipulates that the adoption decision is driven by the perceived characteristics of an innovation. Rogers [59] in his original formulation of the theory focused on an innovation's observability (degree to which the results of an innovation are visible to potential adopters), usefulness ${ }^{1}$ (degree to which the innovation is perceived to be superior to current practice), compatibility (degree to which the innovation is consistent with socio-cultural values, previous ideas, and/or perceived need), trialability (degree to which

\footnotetext{
${ }^{1}$ Originally termed relative advantage
} 
the innovation can be experienced on a limited basis) and ease of use (degree to which an innovation is difficult to use or understand). Moore and Benbasat [47] expanded the range of innovation characteristics considered by including perceived voluntariness (degree to which use of the innovation is perceived as being voluntary, or of free will) and image (extent to which using the innovation was perceived to enhance one's image or status). DOI research originally focused on the impact certain innovation characteristics have on the adoption decision, but further studies have integrated decision maker characteristics to complement the core constructs [67]. Applied to the PA technology adoption context the innovation diffusion perspective suggests that the decision to adopt or not can be explained by the farmer's perception of the characteristics of PA technology.

While a diffusion of innovation perspective focuses on perceived characteristics of an innovation a technology acceptance perspective focuses on behavioral attitudes towards a technology. The focal construct of the technology acceptance model are the perceived ease of use and perceived usefulness of a technology [18]. The model suggests that these two constructs determine an individual's intention to use the technology. Subsequent iterations and applications of the model have shown how these focal constructs successfully mediate the impact of a range of behavioral factors such as level of education or computer selfefficacy [41]. The core tenets of technology acceptance theory have been shown to apply to the context of individuals [33] as well as small firms [29]. Additional studies have conceptualized perceived ease of use and perceived usefulness as mediation variables which in itself are determined by different individual or technology-based factors [e.g. 15]. Venkatesh and Davis [71] hereby confirmed the role of systems knowledge on the formation of ease of use and usefulness perceptions. Applied to the PA context a technology acceptance perspective suggests that a farmers perception of the perceived ease of use and the perceived usefulness of the PA technology not only determines a farmers intention to adopt but also mediates the impact several other individual factors have on the adoption decision. 
Following others $[1,36,54]$ the paper draws on the complementarities of technology acceptance and diffusion of innovation perspectives to enrich the PA adoption model. Building on these established models provides sound theoretical considerations and well-developed constructs [15]. By doing so we do not seek to formally integrate both theories as they co-exist in their own rights and within their own context. The constructs derived from the two theoretical basis are complemented by additional constructs derived from the PA literature. The model and its individual hypothesis are introduced in the following section. The technology attributes are presented first, followed by the organizational attributes.

\subsection{The technology attributes}

The technology attributes describe the range of PA technology related aspects from the perspective of the farmer.

\section{The perceived ease of use of PA technology}

Established IS theory stipulates that the ease with which a particular tool can be employed has a positive impact on the adoption decision. The 'ease of use' influences the attitude towards the technology and eventual technology use [19]. Conversely, the degree to which an innovation is difficult to use inhibits the adoption decision [59]. The PA literature suggests a similar effect of the 'ease of use' of the PA technology on adoption. For instance, Sassenrath [61] explains how a 'prohibitively steep' learning curve negatively impact on the wide-spread adoption of a system. Hence, we hypothesize a direct relationship between the perceived ease of use of PA technology and its adoption:

\section{H1: The ease of use of PA technology positively impacts on its adoption.}

Consistent with Compeau et al. [15] the conceptualization of the PA adoption considers the 'ease of use' as a mediation variable which is determined by other variables. One of the important factors impacting on the perception of 'ease of use' of a technology is its compatibility with existing work-practices [15]. Consistency between existing practices and the technology features positively impact on the 'ease of use' 
perception. In the farming context where operations are characterized by a high degree of routine work and the use of expensive machine equipment, the introduction of a technology that is not compatible with existing practices and infrastructure is likely to be perceived as difficult (especially a type III innovation modifying the work processes). The extent of knowledge about PA technology will also influence the perceived ease of use. Knowledge about the system serves as the basis for judging the ease of use of a technology [71]. In small businesses, the existing expertise of management and employees need to be considered as training-resources are commonly limited [67]. Prior research has highlighted the PA knowledge of the farm owner [17] as well as the PA knowledge of the employee [39] as important adoption factors. In addition to the existing knowledge, research underlines the role of outside help for overcoming the hurdles of the technology, especially in early stages [69]. The PA literature emphasizes how local experts help to provide an initial understanding of the technology [39]. Based on the insights from IS theory and the PA literature we hypothesize that compatibility, farm owner and staff knowledge and quality of support influence the perception of the ease of use of PA technology:

H1a: The compatibility of PA technology positively impacts on the perceived ease of use.

H1b: The quality of support for PA technology positively impacts on the perceived ease of use.

H1c: The farmer's knowledge of PA technology positively impacts on the perceived ease of use.

H1d: The employee's knowledge of PA technology positively impacts on the perceived ease of use.

\section{The perceived usefulness of PA technology}

The technology adoption literature has repeatedly shown that the degree to which a technology is believed to enhance the performance is a strong predictor of its intention to adopt [e.g. 18,34]. Cost-benefit considerations directly affect the decision making process. We assume that comparable decision making considerations apply to the PA context and we hypothesize that the perceived usefulness of the PA technology positively impacts on the adoption decision. 


\section{H2: The perceived usefulness of the PA technology positively impacts on the decision to adopt the PA technology.}

Consistent with other studies [15] that view perceived usefulness as a mediation variable, the following relationships for the PA adoption context are hypothesized. An important determinant of perceived usefulness is the compatibility of a technology with current practices [15]. The more compatible the technology with the existing processes the more relevant it is for the organisation [56]. Aspects of compatibility (f.e. compatibility with existing software) have also been pointed out as one of the core issues experienced in the farming context [39]. Another predictor of usefulness of a technology innovation is the relative advantage it provides in the daily farming process. A technology that is perceived to be superior to the technology that it is replacing has a positive impact on the perception of its usefulness [32]. To distinguish between relative advantage and perceived usefulness the study follows Aubert and Hamel [4] who focus on the overall benefits of the technology and its utility in the individual's routine. Hence, a farmers perception of the generic benefits of PA technology (reduction of inputs, increase productivity, reduction of environmental impact and better information on which to base decision) positively impacts on his or her perception of the technology being useful for the individual context. In addition to the operational benefits information technology can be a source of management information providing input to strategic considerations. However, one of the core challenges in the PA context is for farmers to identify the useful, important and relevant information among the ones gathered [27]. Finally, the perception of the usefulness of a technology is influenced by the extent to which a technology is seen as easy to use $[18,70]$. A technology that is easy to use impacts on the productivity of the user and the overall believe that it helps to enhance the performance in the organizational context [19]. Considering the theoretical and practical aspects we hypothesize that the compatibility, relative advantage, information use and ease of use impact on the perceived usefulness of PA technology.

\section{H2a: The compatibility of the PA technology positively impacts on the perceived usefulness.}


H2b: The relative advantage of the PA technology positively impacts on the perceived usefulness.

H2c: The information of the PA technology positively impacts on the perceived usefulness.

H2d: The ease of use of the PA technology positively impacts on the perceived usefulness.

\section{Other influences on adoption}

Insights from adoption theory and PA literature suggest an additional range of factors that contribute to the PA technology adoption decision. DOI theory stipulates that the extent to which the results of an innovation are visible to potential adopters has a positive impact on the adoption decision [59]. Innovations that are easily communicable (called 'observability' in the DOI literature) are more likely to be adopted. Communicability is expected to be related to perceived ease of use as an innovation's complexity makes it more difficult to demonstrate its functionalities [24] In addition, Moore and Benbasat [47] describe how external pressure impacts the adoption decision with the voluntariness of an innovation reducing the pressure to adopt [1]. DOI theory further stipulates that the extent to which an innovation can be trialed positively impacts on adoption [59] and positive exploratory experiences facilitate the adoption decision [53]. In the PA context frequent trials of PA technology are offered to allow farm owners to experience its benefits (e.g.: http://www.precisionagriculture.com.au/on-farm-research.php). Based on insights from adoption theory and PA literature we hypothesize that the communicability, trialability and voluntariness impact on the PA technology adoption decision:

H3a: Perceived communicability of the PA technology positively impacts on its adoption H3b: Perceived voluntariness of the PA technology negatively impacts on its adoption H3c: Perceived trialability of the PA technology positively impacts on its adoption H3d: Ease of use of the PA technology positively impacts its communicability 


\subsection{The organizational attributes}

The organizational attributes describe factors that are generic to the farm and its management. In small and medium enterprises the attitudes and characteristics of the manager has considerable influence on the organizational decision-making [44] Hence, the innovativeness of the manager (attitude towards innovations that are not fully explored) influences the adoption patterns of a firm [67]. The education-level and age of the manager are also considered in small firm adoption studies [14] but are especially relevant to the farming context as younger farmers have a longer planning horizons, and the education level provides the skills required for experimenting with PA technologies [46]. We hypothesize that the farmer's innovativeness, age and education level impact on the PA adoption decision:

\section{H4a: The farmer's innovativeness positively impacts on PA adoption \\ H4b: The farmer's education level positively impacts on PA adoption \\ H4c: The farmer's age negatively impacts on PA adoption}

The organizational literature has suggested in several studies that firm size and resource availability influence the technology adoption decision [67]. Small firms find it harder to benefit from economies of scale provided from an innovation and the lack of resources lead firms to delay investments. PA adoption studies have suggested that farm size and resource availability have a similar effect on the PA adoption decision. Hence, we can hypothesize the following relationships:

\section{H5a: Farm size has a positive impact on the adoption decision}

\section{H5b: Resource availability has a positive impact on the adoption decision}




\section{METHODOLOGY}

\subsection{Construct development}

For each factor, available measures were identified from the relevant literature. The ones showing higher levels of reliability and validity were used, as long as they could be adapted to the context of precision agriculture. All measures are reflective constructs with items measured by using five point Likert-type scales ranging from "strongly agree" to "strongly disagree", "never" to "always", or "low" to "excellent". The measures have a lower limit of three items since constructs with two items or less tend to be problematic and do not give the flexibility to remove an item to improve reliability [15]. They have an upper limit of 6 items to minimize the number of questions [15]. Cronbach's alpha for each measure needed to be over 0.7 to qualify as reliable [30]. Finally, five pretests were conducted with experts from the field. The first two were academics from the department of agriculture of a large university who validated the appropriateness of the questionnaire from a precision agriculture point of view. The three subsequent validations were with farm owners to ensure that questions were clear and unambiguous.

\subsubsection{Measures}

The measures used to assess the factors are presented in Table 2. The table is organized using the same structure as Section 3. First the measures of technology attributes are outlined. Then, the measures of the organizational attributes are presented.

\section{Table 2 Measures}

\begin{tabular}{|l|l|}
\hline $\begin{array}{l}\text { Variable } \\
\text { (Hypothesis) }\end{array}$ & Justification \\
\hline $\begin{array}{l}\text { Ease of use } \\
\text { (H1, H2d, }\end{array}$ & $\begin{array}{l}\text { Perceived ease of use measures the perception of the ease with which PA technology can be made } \\
\text { usable (or integrated) in daily tasks. The measure proposed by Oh, et al [53] was used because it } \\
\text { showed greater reliability than alternative measures and its items were easily adaptable to the PA } \\
\text { context. }\end{array}$ \\
\hline $\begin{array}{l}\text { Compatibility } \\
\text { (H1a, H2a) }\end{array}$ & $\begin{array}{l}\text { Compatibility of PA technology with work practices and routines was measured following } \\
\text { Oh, et al. [53] as the measure showed good reliability. }\end{array}$ \\
\hline
\end{tabular}




\begin{tabular}{|c|c|}
\hline $\begin{array}{l}\text { Quality of } \\
\text { support (H1b) }\end{array}$ & $\begin{array}{l}\text { Quality of support captures the perception of accessibility, rapidity, and quality of support provided } \\
\text { for PA technology. Aubert and Hamel [4] was adapted to measure quality of support. }\end{array}$ \\
\hline $\begin{array}{l}\text { Operator's } \\
\text { knowledge } \\
\text { (H1c) }\end{array}$ & $\begin{array}{l}\text { Farmer's knowledge captures the extent to which the owner or manager of the farm has knowledge } \\
\text { of information systems and PA technology. To measure farmer's knowledge, Joen, et al's. [35] three } \\
\text { item measure was used. }\end{array}$ \\
\hline $\begin{array}{l}\text { Employees' } \\
\text { knowledge } \\
\text { (H1d) }\end{array}$ & $\begin{array}{l}\text { Employees' knowledge assesses the knowledge that the employees on the farm have of PA } \\
\text { [39]. The measure of Thong [67] was used as three items and shows acceptable reliability levels. In } \\
\text { addition, family labor was included in the items of Thong [67] to complement the measure because } \\
\text { family members an important source of labor in Quebec agricultural industry [16]. }\end{array}$ \\
\hline $\begin{array}{l}\text { Perceived } \\
\text { Usefulness } \\
(\mathrm{H} 2)\end{array}$ & $\begin{array}{l}\text { Perceived usefulness captures the perception of the utility of PA technology and the measure } \\
\text { developed by Aubert and Hamel [4] was used for its assessment. It is one of the two key constructs } \\
\text { of the Technology Acceptance Model [20]. }\end{array}$ \\
\hline $\begin{array}{l}\text { Relative } \\
\text { advantage } \\
(\mathrm{H} 2 \mathrm{~b})\end{array}$ & $\begin{array}{l}\text { Relative advantage was assessed on the basis of four PA based dimensions discussed in the } \\
\text { literature: increased productivity [64], decreased input costs [45], better information on which to } \\
\text { base decisions [45] and reduced environmental impact [73]. Established measures were all too } \\
\text { context specific, which prevented their usage in this study. }\end{array}$ \\
\hline $\begin{array}{l}\text { Information } \\
(\mathrm{H} 2 \mathrm{c})\end{array}$ & $\begin{array}{l}\text { Information measures the perception of the availability, quality, and the value of the } \\
\text { information produced by PA technology. The measure used by Aubert and Hamel [4] was } \\
\text { adapted to make the questions compatible for adopters and non-adopters alike. }\end{array}$ \\
\hline $\begin{array}{l}\text { Perceived } \\
\text { visibility } \\
\text { (H3a) }\end{array}$ & $\begin{array}{l}\text { Visibility describes the extent to which the results obtained from the use of PA technology can be } \\
\text { seen by others [60]. The measures from Oh et al. [53] were modified in order to fit both adopter and } \\
\text { non-adopter. }\end{array}$ \\
\hline $\begin{array}{l}\text { Perceived } \\
\text { voluntariness } \\
\text { (H3b) }\end{array}$ & $\begin{array}{l}\text { Voluntariness captures the degree to which adoption of PA technology is viewed as a matter of } \\
\text { personal choice, rather than external pressure [15]. Compeau et al. [15] was used for its measurement. }\end{array}$ \\
\hline $\begin{array}{l}\text { Perceived } \\
\text { trialability } \\
(\mathrm{H} 3 \mathrm{c})\end{array}$ & $\begin{array}{l}\text { Trialability reflects the ability to use the innovation before adopting it [60]. The measure proposed } \\
\text { by Oh et al. (2003) was used since the alternative [72] was too context specific. The trialability } \\
\text { questions were adapted to the PA context and modified in order to fit both adopter and non-adopter. }\end{array}$ \\
\hline $\begin{array}{l}\text { Farmer's } \\
\text { innovativeness } \\
\text { (H4a) }\end{array}$ & $\begin{array}{l}\text { Farmer's innovativeness assesses the extent to which the farm operator or owner is considered } \\
\text { innovative. [7] was used for its measurement as other available measures }[35,67] \text { were not suitable. }\end{array}$ \\
\hline $\begin{array}{l}\text { Farmers } \\
\text { education } \\
\text { level }(\mathrm{H} 4 \mathrm{~b})\end{array}$ & $\begin{array}{l}\text { This was measured by asking what level of schooling the farmer had completed (Primary school, } \\
\text { secondary school, technical course or community college, university degree, graduate degree) }\end{array}$ \\
\hline $\begin{array}{l}\text { Farmer's age } \\
(\mathrm{H} 4 \mathrm{c})\end{array}$ & $\begin{array}{l}\text { The age variable was divided by decades: less than } 20,20 \text { to } 29,30 \text { to } 39,40 \text { to } 49,50 \text { to } 59,60 \text { and } \\
\text { above. }\end{array}$ \\
\hline $\begin{array}{l}\text { Farm size } \\
(\mathrm{H} 5 \mathrm{a})\end{array}$ & Farm size was measured by the production value, as suggested by Daberkow and Mcbride [17]. \\
\hline $\begin{array}{l}\text { Resource } \\
\text { availability } \\
\text { (H5b) }\end{array}$ & $\begin{array}{l}\text { Resource availability assesses the extent to which individuals believe they have the required } \\
\text { resources to use PA technology [43]. It was measured following Oh et al [53] as other measure [35] } \\
\text { had too few items. }\end{array}$ \\
\hline
\end{tabular}




\subsubsection{Adoption of PA Technologies}

Adoption of PA technologies is measured by a formative construct including seven specific technologies (geographic positioning systems, geographic information systems, yield monitor, yield maps, remotesensing, variable rate application systems, and navigation systems). Respondents indicated which of these tools they were using and the construct was formed using these responses. It can be seen of as a measure of intensity of adoption of PA.

\subsection{Data collection and statistical procedures}

The questionnaire was sent out to 1998 Quebec farm operators in the cereal and oleaginous sectors through their professional association. Once completed, the questionnaire was sent back to the researcher via a prepaid envelope included in the package. Anonymity was thus ensured. Four hundred and thirty eight usable questionnaires were returned for a $21.9 \%$ return rate.

The data was analyzed using Partial Least Squares (PLS). PLS enables the evaluation of the measures as well as the causal model. Instead of simply aggregating measurement errors in a residual error term, PLS simultaneously evaluates both the measurement model and the theoretical model, and adjusts the relationships between the variables accordingly. PLS is appropriate considering the size of the model. It enabled us to obtain meaningful results from the number of responses obtained. The rule of thumb for determining the smallest sample size required to perform PLS analysis is that the sample must comprise ten times the number of items present in the largest construct (or the number of links to one variable) [28]. This requirement was exceeded.

\subsection{Reliability}

Two criteria are used to validate the reliability of the reflective measures: the item loadings on their constructs should be above 0.7 or at least above 0.5 [6], and the Cronbach $\alpha$ of the measure should be above 0.7 [50]. Nine of the 13 measures meet all criteria and need no modification. One item is dropped from the 
ease of use measure. This item inquired about the flexibility of the tools, which can be seen as different from ease of use. One item is dropped from the communicability measure. This item asked about forming an opinion, which is not exactly communicability. The resulting measure of communicability shows acceptable but not stellar reliability. Two items are dropped from the voluntariness and trialability measures. In the first case, the mix of regular and reversed-coding items might have created confusion for the respondents. In the second one, it is difficult to understand why the measure shows limited level of reliability, even in its final form. The final 47 items used all meet the minimal factor loading of 0.5 criteria, and $42 / 47$ meet the more stringent criteria of 0.7 . The properties of the final instruments are shown in Table 3.

Table 3 Reliability and Discriminant Validity of Constructs

\begin{tabular}{|c|c|c|c|c|c|c|c|c|c|c|c|c|c|}
\hline & 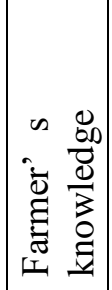 & 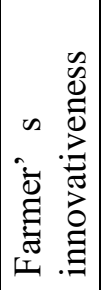 & 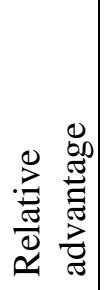 & 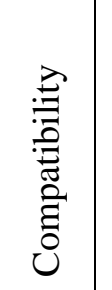 & 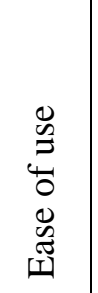 & 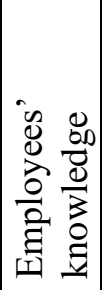 & 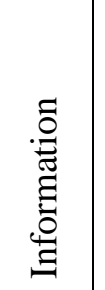 & 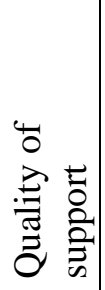 & 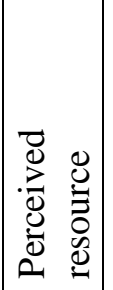 & 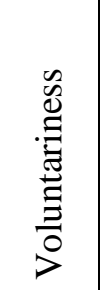 & 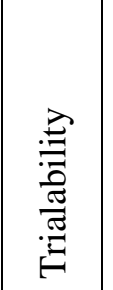 & 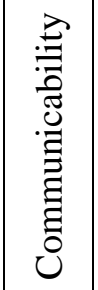 & 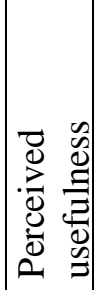 \\
\hline Farmer's knowledge & 0,884 & & & & & & & & & & & & \\
\hline \begin{tabular}{|l|} 
Farmer's \\
innovativeness \\
\end{tabular} & 0.427 & 0,768 & & & & & & & & & & & \\
\hline Relative advantage & 0.257 & 0.424 & 0,788 & & & & & & & & & & \\
\hline Compatibility & 0.525 & 0.572 & 0.590 & 0,875 & & & & & & & & & \\
\hline Ease of use & 0.645 & 0.453 & 0.390 & 0.678 & 0,776 & & & & & & & & \\
\hline Employees' knowledge & 0.314 & 0.256 & 0.270 & 0.427 & 0.444 & 0,857 & & & & & & & \\
\hline Information & 0.284 & 0.276 & 0.434 & 0.450 & 0.469 & 0.358 & 0,835 & & & & & & \\
\hline Quality of support & 0.134 & 0.187 & 0.364 & 0.382 & 0.377 & 0.262 & 0.496 & 0,825 & & & & & \\
\hline Perceived resources & 0.552 & 0.396 & 0.337 & 0.585 & 0.659 & 0.407 & 0.436 & 0.402 & 0,805 & & & & \\
\hline Voluntariness & -0.221 & -0.180 & -0.165 & $-0.358-$ & -0.242 & -0.329 & -0.208 & -0.192 & -0.283 & 0,735 & & & \\
\hline Trialability & 0.068 & 0.105 & 0.199 & 0.185 & 0.223 & 0.089 & 0.151 & 0.140 & 0.179 & -0.081 & 0,848 & & \\
\hline Communicability & 0.352 & 0.346 & 0.250 & 0.401 & 0.438 & 0.214 & 0.282 & 0.153 & 0.417 & -0.124 & 0.476 & 0,739 & \\
\hline Perceived usefulness & 0.348 & 0.494 & 0.517 & 0.650 & 0.489 & 0.329 & 0.422 & 0.334 & 0.425 & -0.284 & 0.164 & 0.367 & 0,801 \\
\hline Adoption (formative) & 0.134 & 0.435 & 0.192 & 0.468 & 0.391 & 0.346 & 0.235 & 0.134 & 0.435 & -0.292 & -0.086 & 0.108 & 0.355 \\
\hline Cronbach $\alpha$ & 0.72 & 0.83 & 0.81 & 0.86 & 0.84 & 0.84 & 0.80 & 0.79 & 0.81 & 0.60 & 0.86 & 0.56 & 0.89 \\
\hline
\end{tabular}




\subsection{Validity}

Adoption is modeled as a formative construct assessing the adoption of the six PA technologies described in Table 1. In order to assess the convergent validity of this construct, the weights of the items provided by PLS are used to create a composite factor score [15]. Significant correlations between the items and this factor score demonstrate convergent validity. Correlations between the items and the factor score that are higher than the correlations between the items and the other constructs indicate discriminant validity [15]. The adoption construct showed such properties. All the other constructs were reflective and could be assessed using traditional procedures.

To assess convergent validity, the average extracted variance (AEV) was computed [25]. AEV was above $50 \%$ for all constructs. The independence of the variables was assessed in two ways. Correlations between constructs were computed. As a rule of thumb, if the correlation between two constructs is greater than 0.7 than there is the possibility of concept overlap. None of the construct pairing showed a correlation above 0.7 (see Table 3). In addition, the square root of the AEV was compared to the correlation between the constructs. The square root of the average variance extracted for the construct should be higher than the correlation between the construct and other constructs [15]. Results in Table 3 show such property.

\section{RESULTS}

The key variable of the PA technology adoption model captures the extent to which PA technologies have been adopted. The adoption variable represents the 'intensity' of PA technology adoption. As expected, the analysis shows that PA technology adoption is determined by the perceived ease of use and usefulness of the PA technology. These two effects are significant and in the expected direction. Adoption is also influenced by resource availability, trialability and voluntariness (negatively), as well as personal characteristics of the farmer (innovativeness and level of education). Contrary to past studies [17], the age of the farmer and the farm size did not have any effect on the adoption. Results are presented in Table 4. 
Table 4 Results

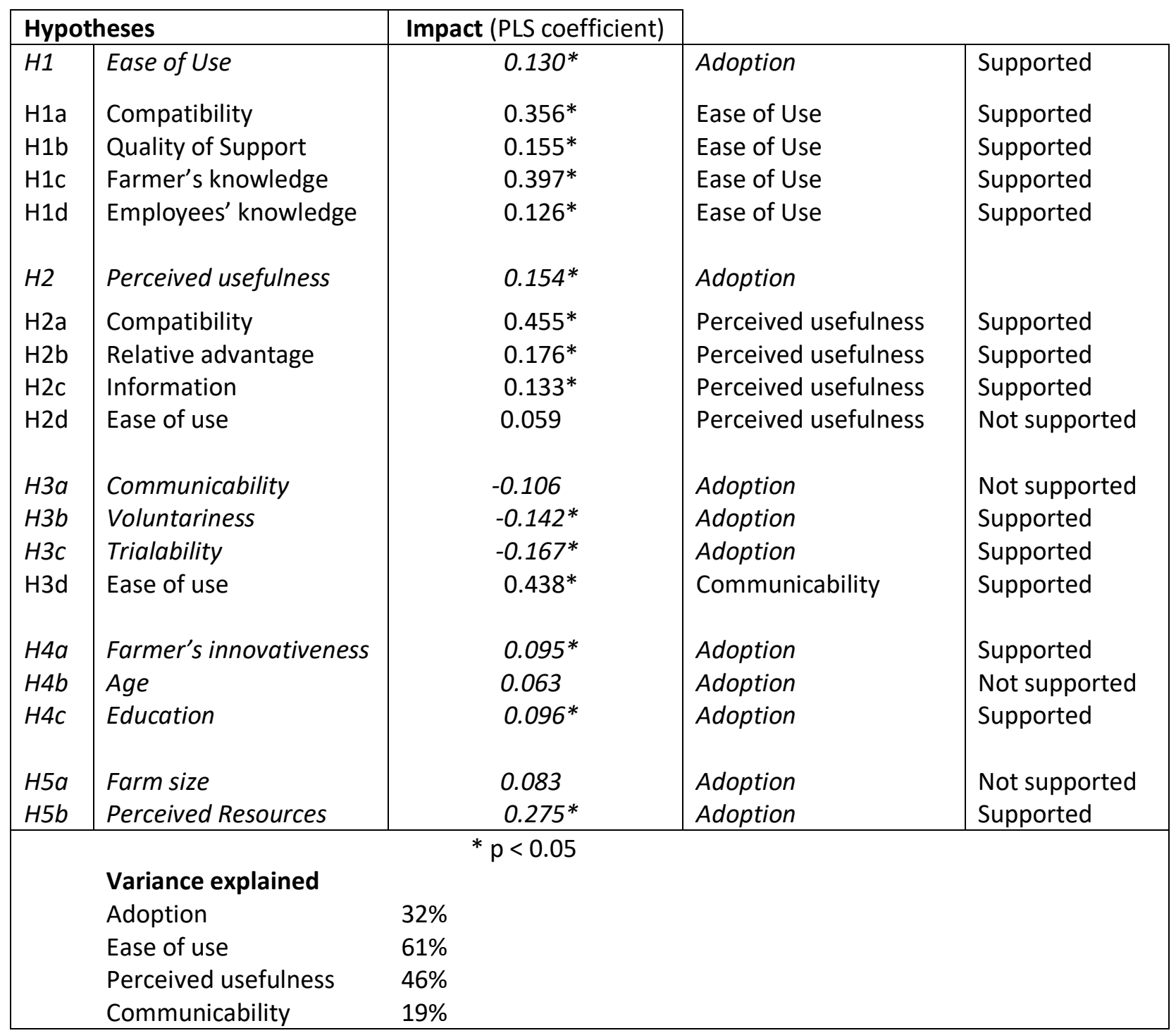

\section{DISCUSSION}

The fact that perceived ease of use and perceived usefulness have a significant effect on PA technology adoption confirms the value of technology acceptance and characteristic of innovation arguments for explaining the variance in the PA technology adoption. It should be emphasized here that measures of usefulness and ease of use focus on the respective perceptions of farmers, which may not necessarily be 
objective assessments of these properties. However, measures of perceptions are likely to be more valuable than out-of-context objective assessments when explaining adoption patterns. It is the decision makers' perception, not an objective outside assessment, which determines the decision to adopt or not a technology [18]. Significant results are discussed in the following pages.

\subsection{The technology attributes}

In the model, the ease of use construct characterizes the extent to which a farmer perceives PA technology to be easy to use. The analysis shows that the farmers' perception on the ease of use of PA technology has a significant impact on its adoption, as expected from past research [38]. A farmer who perceives PA technology as complex or difficult to use is therefore less likely to integrate it into his or her farming operations. Four factors influence the farmers' perception of the PA technology ease of use. All of these factors (knowledge of PA technology, compatibility, quality of support, employees' knowledge) explain more than $60 \%$ of the variance in the farmers' perception of the ease of use of PA technology.

PA technology compatibility with existing farming equipment, routines, and operations is also shown to have a significant effect on the farmers' perception of its ease of use. The more the farmer judges that PA technology is compatible with existing resources, the more likely the farmer will consider PA technology to be easy to use. Through ease of use, the perceived lack of compatibility creates an impediment to PA technology adoption.

The quality of support has a significant impact on the famers' perception of the ease of use of PA technology. The farmers' impression of the ease of use of PA technology is influenced by the quality of support offered by vendors of the technology (or other sources of support like associations). The higher the quality of support provided, the less the farmer perceives PA technology to be difficult to use.

The farmers' knowledge of PA technology has the highest impact on the perception of its ease of use. Hence, the less a farmer knows about PA technology the more likely he or she perceives the use of the 
technology to be difficult. Therefore, the lack of PA technology knowledge seems to be a major reason explaining the farmers' impression that PA technology is difficult and cumbersome to use. Past research efforts outline the value of targeted education programs for promoting PA technology adoption [39]. This would likely increase the farmers' knowledge, and consequently increase the perception that PA technology is easy to use.

The fact that farm employees' knowledge of PA technology has a significant impact on the ease of use construct is of particular interest. This finding suggests that the farmers' perception of the ease of use of PA technology is not only influenced by his or her own expertise of PA technology, but that the knowledge of farm staff is also taken into consideration when forming an opinion on the ease of use of PA technology. While the need for targeted PA education programs has been recognized [39] the focus seems to have been on the farmer, with little consideration for the farm staff. However, implementing PA technology into farming operations requires advanced skills by all individuals involved in the farm operations.

The second core factor that has a significant impact on the PA technology adoption is its perceived usefulness. The perceived usefulness identifies the farmers' perception of the extent to which PA technology usage can improve the farming operations. As expected, the findings confirm that farmers' perception of the PA technology usefulness has a significant impact on the extent of adoption. A farmer who perceives PA technology to provide little direct benefits is therefore less likely to integrate the technology into farming operations. The farmers' perception of the usefulness of PA technology depends on a range of factors. Three factors influencing the farmers' perception of the usefulness of the PA technology have been confirmed: compatibility, information and relative advantage. These factors explain more than $45 \%$ of the variance in the farmers' perception of the usefulness of PA technology.

The analysis shows that PA technology compatibility with existing technology and farming operations had the strongest effect on the farmers' perceived usefulness. This is similar to the effect of compatibility on the perceived ease of use discussed earlier. The higher the compatibility of PA technology with existing 
equipment, routines, and operations, the more likely the farmer will perceive PA technology to be useful. Conversely, the perceived lack of compatibility limits the famers' perception of its usefulness and ultimately constitutes an impediment to PA technology adoption.

While the technology acceptance model hypothesizes a relationship between ease of use and usefulness [39] the present analysis could not find a significant relationship between these two constructs for PA technology. This suggests that the farmers' perception of the usefulness of PA technology is independent of the farmers perception that the technology is easy to use.

The negative impact of voluntariness on adoption suggests that external pressure plays a role in the adoption of PA technology. The literature explains that external pressure can contribute to the adoption of an innovation [1]. Indeed, farmers seem to be receptive to forms of external pressure to use the innovation. Adopters had perceived more pressure to adopt than non adopters.

The negative effect of trialability on PA technology adoption is different from past research results. Prior research suggests that the ease to which a technology can be tried influences the likelihood of its adoption [60]. The negative relationship observed suggests that the farmers who did not adopt the PA technology saw the technology as easier to try than the ones who were actually using it. Therefore, the negative coefficient observed in the sample might suggest that non-adopters have a wrong impression about the possibility to carry out tests of PA technology. They perceived the technology to be easier to try than it really is. Being a complex modularized technology [65] PA tools are not limited to the technology itself but require a wider set of changes in business processes and infrastructure to be experienced and for the benefits to emerge: while individual pieces of equipment might be tested, the innovative character of PA technology will not be experienced by using only one component. It is when all components are used together that the innovation can be experienced. PA technology requires tractors, farming equipment, historical and geo-positioning data, and appropriate software to be interconnected in order to enable 
benefits. The systemic character of the innovation [40] makes it difficult to try, which might explain the counterintuitive results obtained.

\subsection{The organizational attributes}

The innovativeness of the farmer has a significant impact on PA technology adoption. This is aligned with prior studies on information technology adoption. The business-leaders innovativeness is generally considered to have a positive impact on the likelihood of technology adoption [67]. Finally, communicability, the extent to which the benefits of PA technology use can be communicated to others, did not have an impact on the extent of adoption.

The factor that shows the strongest effect on adoption is the perceived extent of resources available. This suggests that, independently of the farmers' perceptions of the technology itself, the adoption decision is also influenced by the farmers' access to appropriate resources (financial or others). The significant effect of resource availability on the adoption decision is in line with prior research. Daberkow and McBride [17] found mixed results when looking at the relationship between credit availability and the adoption decision. Adopters had access to more credit than non adopters, but the relationship was not significant in a Logit regression [17]. The resources assessed in the current survey included financial and other material resources. This suggests that a wider definition of resources is appropriate.

When considering the control variables, the age of the farmer and the size of the farm did not have a significant influence on adoption. The only control variable that was significant was the level of education of the respondent. The level of education had a significant positive effect on adoption.

\section{CONCLUSION}

The present study set out to investigate the adoption of PA technology. PA technology provides opportunities for creating significant efficiencies in farming business operations and contributes to the 
environmental sustainability of farming practices. The diverse benefits of PA technology are widely accepted with ongoing further innovations creating even more sophisticated tools [31]. Thus, the fact that PA technology adoption remains relatively low [9], despite the positive attributes, creates a puzzle. Understanding the circumstances and factors that influence the adoption of PA technology is critical for developing targeted policies or initiatives that support the adoption of this important technology in farming businesses.

Prior investigations on the adoption of PA technology $[46,68]$ have largely focused on determining the impact of individual farm and owners characteristics with little attention to the diverse factors and complex interactions that characterize an adoption decision. The present study significantly advances our understanding of PA technology adoption by drawing on established adoption theory and focusing on individual perceptions as important drivers of the adoption decision. Independent from farm- and owner characteristics, for PA technology adoption to occur the farmer has to perceive the technology as useful and easy to use. It might be insufficient to have positive outside data on the economic benefits of PA technology as perceptions of farmers have to reflect these economic considerations. By integrating the perceptions of the technology with farm and owner characteristics our model describes and confirms the impact of a diverse range of factors on a farmer's adoption decision. The new insights create a number of important implications for policy makers, technology vendors and the IS research community.

\subsection{Research contribution}

The study offers interesting contributions to theory and research. By integrating a wider range of adoption factors the study draws on the complementary aspects of individual adoption theories. The range of factors influencing the adoption process, especially in the case of innovations tightly linked with work processes, is more complex and multi-facetted than what is represented by a technology acceptance perspective or a diffusion of innovation perspective alone. The present study joins a number of authors $[1,36,54]$ who draw 
on both theoretical perspectives and utilize their complementary features in order to understand a complex adoption scenario.

This study gives also insights into the examination of technology that has a complex and systemic character. Although IT innovations are often composed of multiple modules, the vast majority of studies explore the adoption phenomenon with a reference to an individual tool like personal work stations [47] or the web [1] or technologies that do not require significant changes in related processes or equipment, like the adoption of on-line shopping [10]. The adoption of technology that is composed of several partially dependent components can be expected to follow different patterns. As observed in the results, the adoption of PA technology showed counter-intuitive results with respect to trialability and the relationship between ease of use and usefulness. Further exploration of such systemic innovations would refine our understanding of the process and the conditions leading to the adoption of these configurations.

The study further opens up the agricultural sector as an important area of IS research. The IS research attention is largely concentrated on manufacturing, IT, banking, and retail industries [13]. These authors noted the lack of research about IT in the agriculture industry. However, IT is of increasing importance in the agricultural sector with innovations being more and more IT based. The agricultural industry creates a very distinct environment for technology adoption and use which can be expected to challenge and improve established theories. Furthermore, today's urgency related to food security and environmental protection creates an opportunity for IS research to provide substantial contributions reaching beyond a specific industry.

\subsection{Policy implications}

Farming generates a tension between the profit objectives of the farmers, the social benefit of secure food production, and the environmental damages created by pesticides, fertilizer, and intensive land use [51]. As PA technology is able to reconcile production requirements and environmental protection questions arise 
on how best to support the adoption. Our findings suggest opportunities for development of regulation and standards, the establishment of coordination bodies and linkages with national strategies.

\subsubsection{Regulation}

Our study shows that voluntariness does not increase adoption (on the contrary, the relationship is negative, which matches findings from Agarwal and Prasad [1]. This suggests that regulation might be efficient and necessary to advance PA technology adoption. Reducing voluntariness and increasing the constraints would likely increase adoption. Adequate regulation making use of the information provided by PA technology could put more emphasis on accurate reporting of pesticide and fertilizer use, providing farmers with a stronger incentive to implement PA technology. Using PA technology, farmers can report easily the use of any product, the location of its use, and the conditions prevailing during its use. PA technology would lower the administrative burden for the technology savvy producers. While our study shows that the farmers decision to adopt is sensitive to external pressure, insights from the literature mandate that such external pressure needs to be followed by direct benefits to ensure ongoing use [1].

\subsubsection{Standards}

An additional avenue suggested by our data for increasing the adoption of PA technology is the need for compatibility among tools (affecting both 'ease of use' and 'usefulness' of PA technology). For precision agriculture to work, all pieces of the equipment have to work together. From sensors, tractors, computers, GPS, etc., all need to be integrated. Relevant standards have been lacking in the industry so far [55]. Standards would increase compatibility between different pieces of equipment and between equipment from different manufacturers. Standardization could also reduce the path dependency often observed in farming equipment [63] and would ensure that farmers are not held hostage of specific technologies or manufacturers. Our findings showed that 'compatibility of the technology' had the strongest influence on the perceived usefulness of the technology and very strong influence on ease of use. Hence, the 
establishment of standards that match farmers' practice would maximize compatibility, which would in turn increase both perceived usefulness and ease of use, and ultimately increase adoption. The current lack of standards and the heavy requirements for compatibility may explain the lack of a significant link between ease of use and perceived usefulness. The compatibility requirements are so strong (and currently lacking) that the marginal contribution of ease of use may be impossible to detect in the model.

\subsubsection{Coordination entity}

Precision agriculture involves a diversity of stakeholders with little coordination among them: individual farmers, associations and cooperatives, government and equipment vendors. Each group has a perspective on the development of PA technology. A coordinating entity could help integrating the respective views of these stakeholders and ensure better development of PA. Such coordinating entity could also establish training programs for farmers and their employees, enabling economies of scale. Cooperatives and farmers associations would probably be well placed to coordinate such initiatives. They already have close relationships with the farmers, and are likely to be perceived as more trustable than the equipment vendors, who have a vested interest in seeing their own technology adopted.

Our data clearly indicates how specific training programs can impact on the PA adoption process. Operator's knowledge is the strongest predictor of ease of use. If a training program for farmers can be successfully established, it is likely to increase perceived ease of use and facilitate adoption. Combined with standardization, larger knowledge enhancement programmes would enable an easier adoption. Standardization would permit training to be valuable irrespectively of the specific manufacturer selected by the farmer. Training programmes, however, should not be limited to farmers but should also include all farm staff, considering that employees' knowledge has an effect on the farmers' perception of the ease of use of PA technology (as shown in Table 4). 


\subsubsection{National IT Strategy}

Efforts in national IT strategies have generally been focusing on infrastructure and broadband access in remote areas [52]. The existence of an infrastructure will not generate benefits for the society without applicative content. Precision agriculture is such an applicative content and the integration of PA technology with the generic IT infrastructure deployed could increase adoption. As seen in Table 4, perceived resources is the most influential factor directly influencing adoption. Rural areas often have difficulties gaining access to specialized resources able to implement, configure, and support IT systems. By linking the development of PA technology with a national IT strategy, such resources would be identified and their availability would be increased (or at least more predictable). This would increase the perceived resources, which would likely increase adoption.

\subsection{Implications for vendors}

Vendors also form an important part of the adoption environment. As explained before, the extent to which PA technology is compatible with existing farming technologies and practices has a significant effect on the farmers' perception of its ease of use and usefulness. Technology vendors are therefore advised to further enhance the compatibility of their technologies and adjust their designs to provide farmers with technology that is easy to integrate with current work routines. The importance of compatibility identified in this study suggests that the trend towards open standards in PA technology [49] is an important development that vendors should consider. By following open standards and increasing the compatibility of tools technology vendors would enhance farmers' perception of PA technology and ultimately increase their market.

In summary, the study investigates a sector of IT applications that is too rarely studied. It enables the development of a complex adoption model, reflecting the integration of the technology with the tools and work processes used by farmers. The role of compatibility in such integrated environment becomes very 
important. Results highlight the numerous relationships between the variables influencing the adoption of PA technology. The results also suggest policy elements that help promote the adoption of PA technology. Regulations can use PA to monitor more effectively the use of potential contaminants and can be implemented to entice farmers to adopt PA technology and better farming practices. Coordination between stakeholders would facilitate training of farmers and their employees and would also permit a much needed standardization of the PA equipment. These elements would enable both farmers and society in general to benefit from these IT innovations.

\section{REFERENCES}

[1] R. Agarwal, J. Prasad, The role of innovation characteristics and perceived voluntariness in the acceptance of information technologies, Decision Sciences. 28 (1997) 557-582.

[2] S.S. Alam, A. Khatibi, M.I.. Ahmad, H.B. Ismail, Factors affecting e-commerce adoption in the electronic manufacturing companies in Malaysia, International Journal of Commerce and Management. 17 (2008) 125-139.

[3] B.C. Atherton, M.T. Morgan, S.A. Shearer, T.S. Stombaugh, A.D. Ward, Site-specific farming: A perspective on information needs, benefits and limitations, Journal of Soil and Water Conservation. 54 (1999) $455-461$.

[4] B.A. Aubert, G. Hamel, Adoption of smart cards in the medical sector: the Canadian experience, Social Science \& Medicine. 53 (2001) 879-894.

[5] H. Auernhammer, Precision farming-the environmental challenge, Computers and Electronics in Agriculture. 30 (2001) 31-43.

[6] D. Barclay, C. Higgins, R. Thompson, The partial least square (PLS) approach to casual modeling: Personal computer adoption and use as an illustration, Technology. 2 (1995) 285-309.

[7] T. Bhatti, Exploring factors influencing the adoption of mobile commerce, Journal of Internet Banking and Commerce. 12 (2007) 1-13.

[8] R. Bongiovanni, J. Lowenberg-DeBoer, Precision agriculture and sustainability, Precision Agriculture. 5 (2004) 359-387.

[9] R.G.V. Bramley, Lessons from nearly 20 years of Precision Agriculture research, development, and adoption as a guide to its appropriate application, Crop and Pasture Science. 60 (2009) 197-217.

[10] M.K. Chang, W. Cheung, V.S. Lai, Literature derived reference models for the adoption of online shopping, Information \& Management. 42 (2005) 543-559.

[11] P.Y.K. Chau, Inhibitors to EDI adoption in small businesses: An empirical investigation, Journal of Electronic Commerce Research. 2 (2001) 78-88.

[12] P.Y.K. Chau, K.L. Hui, Determinants of small business EDI adoption: an empirical investigation, Journal of Organizational Computing and Electronic Commerce. 11 (2001) 229-252.

[13] M.W. Chiasson, E. Davidson, Taking industry seriously in information systems research, Mis Quarterly. 29 (2005) 591-605.

[14] T.T. Chuang, M.W. Rutherford, B. Lin, Owner/manager characteristics, organisational characteristics and IT adoption in small and medium enterprises, International Journal of Management and Enterprise Development. 4 (2007) 619-634. 
[15] D.R. Compeau, D.B. Meister, C.A. Higgins, From Prediction to Explanation: Reconceptualizing and Extending the Perceived characteristics of innovating, Journal of the Association for Information Systems. 8 (2007) 409-439.

[16] CRAAQ, Portrait de l'établissement et du retrait de l'agriculture au Québec, Centre de référence en agriculture agroalimentaire du Québec, Sainte-Foy, 2004.

[17] S.G. Daberkow, W.D. McBride, Farm and operator characteristics affecting the awareness and adoption of precision agriculture technologies in the US, Precision Agriculture. 4 (2003) 163-177.

[18] F.D. Davis, Perceived usefulness, perceived ease of use, and user acceptance of information technology, MIS Quarterly. 13 (1989) 319-340.

[19] F.D. Davis, User acceptance of information technology: system characteristics, user perceptions and behavioral impacts, 38 (1993) 475-487.

[20] F.D. Davis, R.P. Bagozzi, P.R. Warshaw, User acceptance of computer technology: a comparison of two theoretical models, Management Science. 35 (1989) 982-1003.

[21] Q. Du, N.-B. Chang, C. Yang, K.R. Srilakshmi, Combination of multispectral remote sensing, variable rate technology and environmental modeling for citrus pest management, Journal of Environmental Management. 86 (2008) 14-26.

[22] G. Feder, D.L. Umali, The adoption of agricultural innovations:: A review, Technological Forecasting and Social Change. 43 (1993) 215-239.

[23] R.G. Fichman, Information technology diffusion: a review of empirical research, in: Proceedings of the 13th International Conference on Information Systems, Dallas, 1992: pp. 195-206.

[24] L.A. Fidler, J.D. Johnson, Communication and innovation implementation, Academy of Management Review. 9 (1984) 704-711.

[25] C. Fornell, D.F. Larcker, Evaluating structural equation models with unobservable variables and measurement error, Journal of Marketing Research. 18 (1981) 39-50.

[26] S. Fountas, S. Blackmore, D. Ess, S. Hawkins, G. Blumhoff, J. Lowenberg-Deboer, et al., Farmer experience with precision agriculture in Denmark and the US Eastern Corn Belt, Precision Agriculture. 6 (2005) 121-141.

[27] S. Fountas, D. Wulfsohn, B.S. Blackmore, H.L. Jacobsen, S.M. Pedersen, A model of decisionmaking and information flows for information-intensive agriculture, Agricultural Systems. 87 (2006) 192-210.

[28] A. Gopal, R.P. Bostrom, W.W. Chin, Applying adaptive structuration theory to investigate the process of group support systems use, Journal of Management Information Systems. 9 (1992) 45-69.

[29] E.E. Grandon, J.M. Pearson, Electronic commerce adoption: an empirical study of small and medium US businesses, Information \& Management. 42 (2004) 197-216.

[30] J.F. Hair Jr, R.E. Anderson, R.L. Tatham, W.C. Black, Multivariate data analysis: with readings, Prentice-Hall, Upper Saddle River, NJ, 1995.

[31] J. Hassall, Future Trends in Precision Agriculture - A look into the future of agricultural equipment, 2010.

[32] M. Hebert, I. Benbasat, Adopting information technology in hospitals: the relationship between attitudes/expectations and behavior., Hospital \& Health Services Administration. 39 (1994) 369-383.

[33] P.J. Hu, P.Y.. Chau, O.R.. Sheng, K.Y. Tam, Examining the technology acceptance model using physician acceptance of telemedicine technology, Journal of Management Information Systems. 16 (1999) 91-112.

[34] M. Igbaria, J. Livari, The effects of self-efficacy on computer usage, Omega. 23 (1995) 587-605.

[35] B.N. Jeon, K.S. Han, M.J. Lee, Determining factors for the adoption of e-business: the case of SMEs in Korea, Applied Economics. 38 (2006) 1905-1916.

[36] E. Karahanna, D.W. Straub, N.L. Chervany, Information technology adoption across time: a crosssectional comparison of pre-adoption and post-adoption beliefs, MIS Quarterly. (1999) 183-213.

[37] M. Khalifa, K.N. Shen, Explaining the adoption of transactional B2C mobile commerce, Journal of Enterprise Information Management. 21 (2008) 110-124. 
[38] W.R. King, J. He, A meta-analysis of the technology acceptance model, Information \& Management. 43 (2006) 740-755.

[39] N.R. Kitchen, C.J. Snyder, D.W. Franzen, W.J. Wiebold, Educational needs of precision agriculture, Precision Agriculture. 3 (2002) 341-351.

[40] L. Langlois Paul, N. Richard, Networks and innovation in a modular system: Lessons from the microcomputer and stereo component industries, Research Policy. 21 (1992) 297-313.

[41] P. Legris, J. Ingham, P. Collerette, Why do people use information technology? A critical review of the technology acceptance model, Information \& Management. 40 (2003) 191-204.

[42] A. Malhotra, N.P. Melville, R.T. Watson, Information Systems and Environmental Sustainability (special issue), MIS Quarterly.

[43] K. Mathieson, E. Peacock, W.W. Chin, Extending the technology acceptance model: the influence of perceived user resources, ACM SIGMIS Database. 32 (2001) 86-112.

[44] H. Matlay, M. Addis, Adoption of ICT and e-commerce in small businesses: an HEI-based consultancy perspective, Journal of Small Business and Enterprise Development. 10 (2003) 321-335.

[45] A. McBratney, B. Whelan, T. Ancev, J. Bouma, Future directions of precision agriculture, Precision Agriculture. 6 (2005) 7-23.

[46] W.D. McBride, S.G. Daberkow, Information and the Adoption of Precision Farming Technologies., Journal of Agribusiness. 21 (2003) 21-38.

[47] G.C. Moore, I. Benbasat, Development of an instrument to measure the perceptions of adopting an information technology innovation, Information Systems Research. 2 (1991) 192-222.

[48] F.F.. Nah, X. Tan, S.H. Teh, An empirical investigation on end-users' acceptance of enterprise systems, Information Resources Management Journal. 17 (2004) 32-53.

[49] E. Nash, P. Korduan, R. Bill, Applications of open geospatial web services in precision agriculture: a review, Precision Agriculture. 10 (2009) 546-560.

[50] J.C. Nunally, I.H. Bernstein, Psychometric theory, New York: McGraw-Hill, 1978.

[51] OECD, Linkages between Agricultural Policies and Environmental Effects Using the OECD Stylised Agri-environmental Policy Impact Model, OECD Publishing, 2010.

[52] OECD, The impact of the crisis on ICTs and their role in the recovery, OECD Publishing, 2009.

[53] S. Oh, J. Ahn, B. Kim, Adoption of broadband Internet in Korea: the role of experience in building attitudes, Journal of Information Technology. 18 (2003) 267-280.

[54] C.R. Plouffe, J.S. Hulland, M. Vandenbosch, Research report: Richness versus parsimony in modeling technology adoption decisions-understanding merchant adoption of a smart card-based payment system, Information Systems Research. 12 (2001) 208-222.

[55] Precision AG, Stepping forward on precision agriculture standards, (2011).

[56] G. Premkumar, K. Ramamurthy, S. Nilakanta, Implementation of electronic data interchange: an innovation diffusion perspective, Journal of Management Information Systems. (1994) 157-186.

[57] B. Recio, F. Rubio, J.A. Criado, A decision support system for farm planning using AgriSupport II, Decision Support Systems. 36 (2003) 189-203.

[58] M. Reichardt, C. Jürgens, U. Klöble, J. Hüter, K. Moser, Dissemination of precision farming in Germany: acceptance, adoption, obstacles, knowledge transfer and training activities, Precision Agriculture. 10 (2009) 525-545.

[59] E.M. Rogers, Diffusion of Innovations, Free Press, Glencoe, 1962.

[60] E.M. Rogers, Diffusion of Innovations, Free Press, New York, 2003.

[61] G. Sassenrath, P. Heilman, E. Luschei, G. Bennett, G. Fitzgerald, P. Klesius, et al., Technology, complexity and change in agricultural production systems, Renewable Agriculture and Food Systems. 23 (2008) 285-295.

[62] D. Schimmelpfennig, R. Ebel, On the Doorstep of the Information Age, United States Department of Agriculture, 2011. 
[63] A. Sharma, A. Bailey, I. Fraser, Technology Adoption And Pest Control Strategies Among UK Cereal Farmers: Evidence from Parametric and Nonparametric Count Data Models, Journal of Agricultural Economics. 62 (2011) 73-92.

[64] C.B. Silva, S.M.L.. do Vale, F.A.. Pinto, C.A.. Müller, A.D. Moura, The economic feasibility of precision agriculture in Mato Grosso do Sul State, Brazil: a case study, Precision Agriculture. 8 (2007) 255-265.

[65] E.B. Swanson, Information systems innovation among organizations, Management Science. 40 (1994) 1069-1092.

[66] H.H. Teo, K.K. Wei, I. Benbasat, Predicting intention to adopt interorganizational linkages: an institutional perspective, MIS Quarterly. 27 (2003) 19-41.

[67] J.Y.. Thong, An integrated model of information systems adoption in small businesses, Journal of Management Information Systems. 15 (1999) 187-214.

[68] J.C. Torbett, R.K. Roberts, J.A. Larson, B.C. English, Perceived importance of precision farming technologies in improving phosphorus and potassium efficiency in cotton production, Precision Agriculture. 8 (2007) 127-137.

[69] V. Venkatesh, Determinants of perceived ease of use: Integrating control, intrinsic motivation, and emotion into the technology acceptance model, Information Systems Research. 11 (2000) 342-365.

[70] V. Venkatesh, H. Bala, Technology acceptance model 3 and a research agenda on interventions, Decision Sciences. 39 (2008) 273-315.

[71] V. Venkatesh, F.D. Davis, A model of the antecedents of perceived ease of use: Development and test*, Decision Sciences. 27 (1996) 451-481.

[72] T.T.. Wee, Factors affecting new product adoption in the consumer electronics industry, Singapore Management Review. 25 (2003) 51-71.

[73] N. Zhang, M. Wang, N. Wang, Precision agriculture-a worldwide overview, Computers and Electronics in Agriculture. 36 (2002) 113-132.

[74] K. Zhu, K. Kraemer, S. Xu, Electronic business adoption by European firms: a cross-country assessment of the facilitators and inhibitors, European Journal of Information Systems. 12 (2003) 251-268. 